\title{
Erratum to: Surgical therapy of neuroendocrine neoplasm with hepatic metastasis: patient selection and prognosis
}

\author{
F. M. Watzka • C. Fottner • M. Miederer • A. Schad • \\ M. M. Weber • G. Otto $\cdot$ H. Lang $\cdot$ T. J. Musholt
}

Published online: 7 April 2015

(C) Springer-Verlag Berlin Heidelberg 2015

\section{Erratum to: Langenbecks Arch Surg}

DOI 10.1007/s00423-015-1277-z

Figure 5 is not visible in the published online version. The correct figure and caption is shown below.

The online version of the original article can be found at http://dx.doi.org/ 10.1007/s00423-015-1277-z.

\section{F. M. Watzka $\cdot$ H. Lang $\cdot$ T. J. Musholt $(\bowtie)$}

Clinic of General, Visceral and Transplantation Surgery, University

Medical Center University Mainz, Langenbeckstr. 1,

55131 Mainz, Germany

e-mail: musholt@uni-mainz.de

C. Fottner $\cdot$ M. M. Weber

Clinic of Endocrinology and Metabolic Diseases, University Medical

Center University Mainz, Langenbeckstr. 1, 55131 Mainz, Germany

M. Miederer

Clinic of Nuclear Medicine, University Medical Center University

Mainz, Langenbeckstr. 1, 55131 Mainz, Germany

\section{A. Schad}

Institute of Pathology, University Medical Center University Mainz, Langenbeckstr. 1, 55131 Mainz, Germany

G. Otto

Clinic of Transplantation Surgery, University Medical Center

University Mainz, Langenbeckstr. 1, 55131 Mainz, Germany

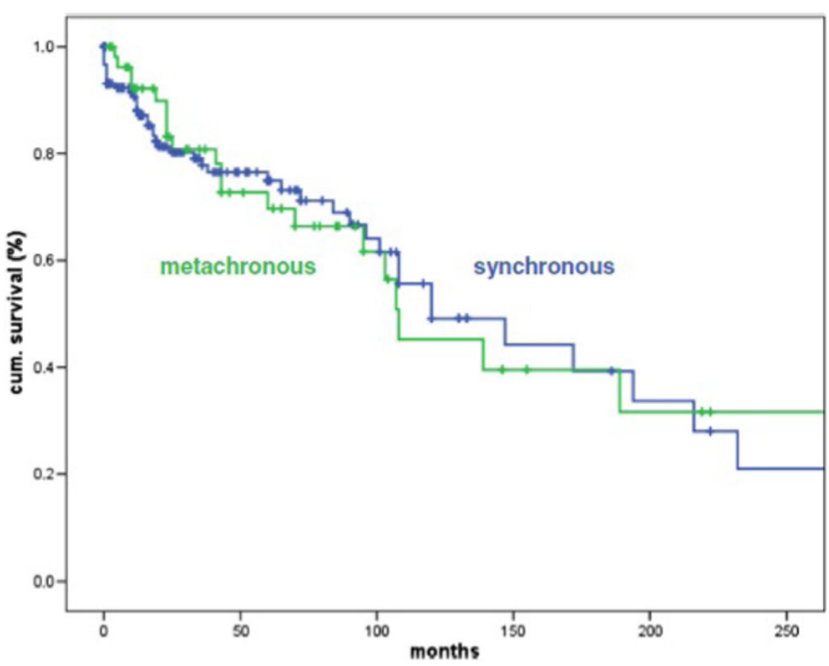

Fig. 5 Kaplan-Meyer curve according to synchronous $(n=150)$ or metachronous $(n=54)$ occurrence of the hepatic metastases. There is no significant difference between the curves ( $\log$ rank test $p=0.834$ ). The 10 year survival rates were $55.7 \%$ for synchronous and $45.2 \%$ for metachronous hepatic metastases 